\title{
Congenital adrenal hyperplasia: Diagnostic advances
}

\section{T. Torresani • Anna Biason-Lauber}

Published online: 30 August 2007

(C) SSIEM and Springer 2007

Erratum to: J Inherit Metab Dis 2007; 30: 563-575.

DOI 10.1007/s10545-007-0696-6

Figures 6 and 7 are wrong in this article. The existing Fig. 7 should be Fig. 6. The legend for Fig. 6 is correct. The correct Fig. 7 is:

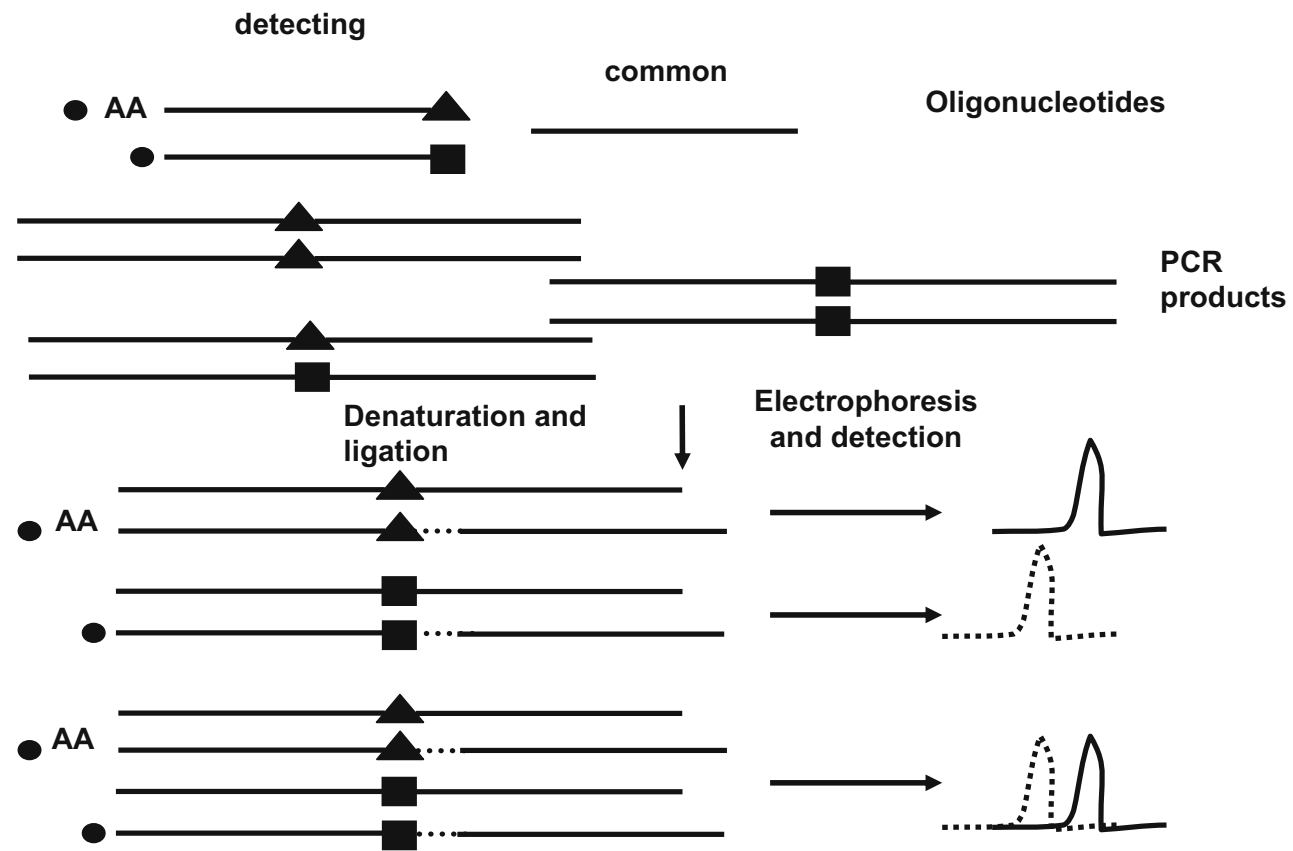

Fig. 7 Ligase detection reaction: principle. Detecting (or allelespecific) oligonucleotides and one common oligonucleotide are hybridized to denatured PCR-amplified targets. The detecting oligonucleotides anneal immediately adjacent to the $5^{\prime}$-end of the common oligonucleotide, resulting in the formation of a
shortDNA duplex containing a nick at the junction site between the primers. If there is a match, then the junction between the detecting and the common primers will be covalently sealed by DNA ligase. We chose to differentiate the multiplex LDR products on the basis of length and labelling (see text for further details)

The online version of the original article can be found at http://dx.doi.org/10.1007/s10545-007-0696-6

T. Torresani $(\bowtie)$

Steinwiesstrasse 75 ,

CH-8032 Zurich, Switzerland

e-mail: Toni.Torresani@kispi.uzh.ch
T. Torresani $\cdot$ A. Biason-Lauber

Department of Endocrinology and Diabetology,

University Children's Hospitals,

Zurich, Switzerland 